\title{
Transient evoked otoacoustic emissions (TEOAEs) in new-borns: normative data
}

\author{
G. Paludetti ${ }^{\text {a,* }}$, F. Ottaviani ${ }^{\text {a }}$, A.R. Fetoni ${ }^{\text {a }}$, A.A. Zuppa ${ }^{\text {b }}$, G Tortorolo ${ }^{\text {b }}$ \\ ${ }^{\text {a }}$ ENT Institute, Catholic University of the Sacred Heart, Rome, Italy \\ b Pediatric Institute, Catholic University of the Sacred Heart, Rome, Italy
}

Received 9 August 1998; received in revised form 18 November 1998; accepted 22 November 1998

\begin{abstract}
Objective: Early diagnosis and rehabilitation of congenital hearing loss are mandatory in order to achieve a satisfactory linguistic and cognitive development. A universal hearing screening in order to identify congenital hearing losses before 3 months of age is required. Methods: TEOAEs are an easy to perform, short lasting, not invasive and low-cost test with a high sensitivity. 320 at term new-borns (640 ears) without any risk factor for hearing loss underwent TEOAEs. The new-borns were screened 3 days after birth. Those who failed the first test were retested when possible before the discharge from the hospital. ABR was performed 3 months later in cases who failed TEOAE. Results: The median TEOAE sampling time was $98 \mathrm{~s}$, the median test duration was 14 min. The mean stimulus amplitude was $80 \mathrm{~dB}$ peSPL in the left ear and $81 \mathrm{~dB}$ peSPL in the right ear, noise levels within the external meatus during sampling were $44 \mathrm{~dB}$ SPL on the right ear and $43 \mathrm{~dB}$ SPL on the left one, noise contained within the response (A-B difference) was $8.65 \mathrm{~dB}$ SPL in the left ear and $8.74 \mathrm{~dB}$ SPL in the right ear, mean TEOAEs amplitudes were $21.49 \mathrm{~dB}$ SPL and $21.78 \mathrm{~dB}$ SPL in the right and left ear respectively, the mean lower and upper limit of the spectrum being 678 and $5720 \mathrm{~Hz}$. According to these criteria 494/640 ears $(77.2 \%)$ passed the test at the first recording, while TEOAEs resulted to be absent in 146/640 ears (22.8\%). A retest was performed successfully before the discharge from the Hospital in 30/640 ears (4.7\%). An ABR recording within the third month of life was scheduled as out-patient in the 58 new-borns (116 ears, 18.2\%) who failed the test. 18 of them (36 ears, 5.6\%) did not complete the program, 19 new-borns (38 ears, 11.8\%) showed a normal ABR, while two new-borns (four ears, $0.6 \%$ ) failed ABR after 3 months. A second ABR performed after 6 months was normal. Conclusions: TEOAEs recording seems at now the test of choice for a universal hearing screening. However, a greater standardization of criteria both in performing the test and in evaluating the results is needed. (C) 1999 Elsevier Science Ireland Ltd. All rights reserved.
\end{abstract}

Keywords: New-borns; Screening; Transient evoked otoacoustic emissions

* Corresponding author. Fax: + 39-06-305-1194. 


\section{Introduction}

A successful neonatal hearing screening program should detect hearing losses that will interfere with a satisfactory linguistic and cognitive development. Because normal hearing is critical for speech and oral language development during the first 6 months of life, it is desirable to identify hearing loss before 3 months and to begin treatment by 6 months of age.

In 1994 the Joint Committee on Infant Hearing [1] emphasized the importance of a universal hearing screening in order to identify congenital hearing losses because a risk factor screening identifies only $50 \%$ of new-borns with significant hearing loss. A hearing loss greater than $30 \mathrm{~dB}$ HL in the frequency range important for speech recognition (approximately $500-4000 \mathrm{~Hz}$ ) will interfere with the normal development of speech and language [2-5].

Since 1978, when Kemp [6] was able to record within the external auditory canal a sound pressure variation $5 \mathrm{~ms}$ after the stimulus delivery by means of a miniaturized microphone, the universal neonatal hearing screening has become the main field of interest of the 'otoacoustic emissions' [7,8].

It is now well known that otoacoustic emissions represent a part of the energy produced within the inner ear and more specifically by the outer hair cells. Such energy can be recorded within the external ear canal following a retrograde pathway through the ossicular chain and the tympanic membrane. Their presence seems to demonstrate a normal function of the outer hair cells and they are absent in ears with hearing loss greater than $40 \mathrm{~dB}[2,9,10]$.

Otoacoustic emissions can be spontaneous (SOAEs), evoked by transient stimuli such as clicks or tone bursts (TEOAEs) and distortion products (DPOAEs). TEOAEs are not invasive and easy to perform, the time needed to their recording is short, the cost is low and their sensitivity is high. For these reasons they are at present considered the test of choice for the first level neonatal screening, while ABR represents the second level and should be employed in cases who fail TEOAEs. Aim of the present study was to relate the results obtained by means of TEOAEs in an at-term new-born population and to discuss the criteria used both for stimulation and for response analysis comparing them with those reported in the literature.

\section{Materials and methods}

During 1997, after a period of training in 1996, we have carried out TEOAE measurements on 320 at term new-borns ( $N=640$ ears) without any risk for hearing loss as defined by the 'Committee on Infant Hearing' in the Nursery of the Catholic University of the Sacred Heart of Rome. All of them were bilaterally tested $(N=640$ ears).

The new-borns were screened 3 days following birth after a clinical evaluation including otoscopy, in order to determine the presence of 'vernix caseosa' occluding the external meatus or a middle ear effusion.

The ILO88 Otodynamic Analyzer introduced by Kemp and Bray was used for testing.

A probe fitting into new-born ears was placed into the external ear canal. Stimuli were $75-85 \mathrm{~dB}$ peSPL $80 \mu$ s duration clicks, with a flat acoustic spectrum between 0.6 and $5 \mathrm{kHz}$, presented at a rate of $50 \mathrm{stim} / \mathrm{s}$.

Stimulus stability reflecting changes of the stimulus intensity occurring during the test, was calculated every $3 \mathrm{~s}$ and was never lower than $75 \%$ of the initial stimulus.

The differential non-linear test paradigm was used. The stimulus was characterized by a train of four clicks, three with the same amplitude and polarity, followed by a fourth one with a 3-fold greater amplitude and an opposite polarity. Responses were represented by an average of a maximum of 260 click stimuli trains (1040) stored into two different buffers (A and B) for a total of 2080 clicks.

In order to establish numerical pass criteria for TEOAEs, the following parameters were used in combination:

1. Response amplitude.

2. The cross-correlation of the two waveforms (wholerepro).

3. OAEs spectrum. 
The frequency-domain analysis was determined by performing the fast Fourier transformation of the two buffers. During the registration the noise rejection thresholds were adjusted by the examiner to obtain the cleanest signal.

The TEOAE test was considered passed when the whole response reproducibility was equal or greater than $50 \%$ and the amplitude of the response exceeded significantly the background noise in at least three of the five frequency bands.

The new-borns were examined in a quiet room in the nursery during spontaneous sleep about 30 min after meal.

TEOAEs probe was placed delicately to seal the wall of the external meatus. When the probe was correctly inserted, the stimulus waveform was biphasic and decayed rapidly.

Increased oscillations ('ringing') were due to a poor probe fit, to debris occluding the ear canal, or to excessive stimulus intensity levels.

When the probe was occluded by vernix caseosa, it was removed, cleaned and replaced.

Sometimes the external canal was collapsed because of the soft tissues and a repeated placement of the probe improved coupling between the ear canal and the probe.

The stimulus intensity gain never exceeded 3 dB.

The following parameters were considered:

1. TEOAEs sampling.

2. TEOAEs recording time.

3. Stimulus amplitude.

4. Noise levels within the external meatus during sampling.

5. Noise within the response ( $\mathrm{A}-\mathrm{B}$ difference).

6. Mean TEOAEs amplitude.

7. TEOAEs spectrum.

8. percent reproducibility (cross-correlation between $\mathrm{A}$ and $\mathrm{B}$ waveforms).

The results of the investigation in terms of pass-fail, sensitivity and specificity were evaluated following these criteria.

\section{Results}

The mean sampling time resulted $110 \pm 59.4 \mathrm{~s}$, (median $98 \mathrm{~s}$, range $41-390 \mathrm{~s}$ ). The mean test duration for both ears was $13.9 \pm 2.3 \mathrm{~min}$, (median $14 \mathrm{~min}$, range 6-20 $\mathrm{min}$ ) (Table 1). In 13\% of cases it reached $20 \mathrm{~min}$ while in $7 \%$ the time needed for the check fit exceeded $20 \mathrm{~min}$ and the test was delayed at the end of the session. The increased duration of the test was due to the spontaneous motor activity, to the rewakening during the probe fit, to the environmental and biological noise levels and more frequently to the time needed to clean the external auditory meatus with a small ear swab or with repeated placements of the probe.

The mean peak stimulus level was $80 \mathrm{~dB}$ peSPL in the left ear and $81 \mathrm{~dB}$ peSPL in the right ear (Table 1). The mean noise levels in the right and left ear canals were 44 and $43 \mathrm{~dB}$ SPL, respectively (Table 1). The $\mathrm{A}-\mathrm{B}$ difference (noise contained within the response) was $8.65 \mathrm{~dB}$ SPL in the left ear and $8.74 \mathrm{~dB}$ SPL in the right ear (Table 1).

The mean amplitude of TEOAEs was 21.49 and $21.78 \mathrm{~dB}$ SPL in the right and left ear, respectively, and their distribution is showed in Fig. 1. Mean response reproducibility resulted to be $84 \%$ for the right ear and $88 \%$ for the left ear (Table 1). Concerning the spectral content of TEOAEs, the mean lower limit was $678 \mathrm{~Hz}$, while the upper limit was $5720 \mathrm{~Hz}$.

Table 1

Mean, (S.D.) and median for some of the TEOAE characteristics in new-borns who passed the screening

\begin{tabular}{|c|c|c|}
\hline & $\begin{array}{l}\text { Right ear } \\
\text { (mean and } \\
\text { S.D.) }\end{array}$ & $\begin{array}{l}\text { Left ear (mean } \\
\text { and S.D.) }\end{array}$ \\
\hline Sampling time (s) & $115(59.5) 98^{\mathrm{a}}$ & $110(54.4) 97^{\mathrm{a}}$ \\
\hline Recording time (min) & $13.98(2.3) 14^{\mathrm{a}}$ & $14.3(2.82) 14^{\mathrm{a}}$ \\
\hline $\begin{array}{l}\text { Stimulus level (dB pe- } \\
\text { SPL) }\end{array}$ & $81.13(3.18)$ & $80(6.55)$ \\
\hline $\begin{array}{l}\text { Noise (average) (dB- } \\
\text { SPL) }\end{array}$ & $44.27(4.65)$ & $43.21(4.53)$ \\
\hline $\begin{array}{c}\text { A-B diff. (response } \\
\text { noise) (dBSPL) }\end{array}$ & $8.74(2.0)$ & $8.5(2.5)$ \\
\hline $\begin{array}{l}\text { Amplitude of the re- } \\
\text { sponse (dBSPL) }\end{array}$ & $21.49(5.05)$ & $21.78(5.75)$ \\
\hline Reproducibility (\%) & $84.6(22.8)$ & $88.8(5.5)$ \\
\hline
\end{tabular}

a Median. 


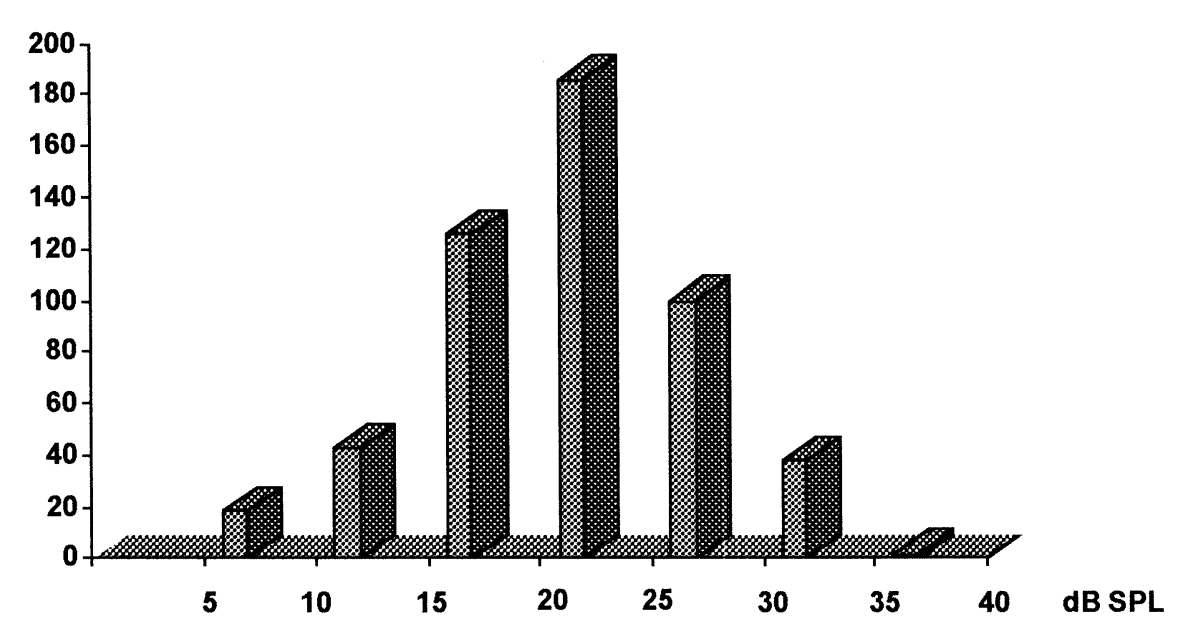

Fig. 1. TEOAEs amplitude distribution in 640 ears. The amplitude ranged between 8.5 and 40.2 dB SPL. The mean amplitude of TEOAE response was $21.49 \mathrm{~dB}$ SPL (S.D. = 5.05) in the right ear and $21.78($ S.D. $=5.75)$ in the left ear.

494 out of 640 ears $(77.2 \%)$ passed the test at the first recording, while TEOAEs were absent in $146 / 640$ ears, with a false alarm rate of $22.8 \%$. In 30 out of 640 ears $(4.7 \%)$ a retest was performed before hospital discharge and all passed the test. An ABR recording within the third month of life was scheduled as out-patient in the 58 new-borns (116 ears, 18.2\%) who failed the test, because they were discharged from the hospital immediately after the first TEOAEs recording. 18 of them (36 ears, 5.6\%) did not complete the program, 19 new-borns (38 ears, 11.8\%) showed a normal ABR, while two new-borns (four ears, 0.6\%) failed ABR after 3 months. A second ABR performed after 6 months was normal.

In the present series TEOAEs sensitivity reached $100 \%$ with a specificity of $77.2 \%$.

\section{Discussion}

Most authors agree that a universal hearing screening has to be performed and that TEOAEs seem to be at present the test of choice, but the test parameters and evaluation criteria have not yet been clearly defined.

Differential non linear (DNLR) stimulation reduces stimulus artifacts and is at now the best way to determine the response within a neonatal hearing screening program $[11,12]$.
Clicks are the most suitable stimuli as their whole frequency range and the response analysis by means of the FFT makes them almost as frequency specific as tone bursts [13,9].

The stimulus intensity used in the present study is similar to that used by other authors [14-18]. The stimulus stability, measured as percent pressure variation every $3 \mathrm{~s}$ and compared to the initial one, should be greater than $75 \%[15,19]$.

Biological and environmental noise exceeding 30 dBA SPL is able to mask TEOAEs [20] and Kemp [9] emphasizes that noise should not exceed $45 \mathrm{~dB}$ SPL. In the present study we were able to keep the noise level below $43 \mathrm{~dB}$ SPL. This was achieved by recording the otoemissions during the new-borns spontaneous sleep and performing the test in a separate room. The lower is the noise level and the shorter is the test duration.

One of the reasons of success of TEOAEs as a new-born auditory screening test is the response amplitude. In the present study the mean response amplitude was $21 \mathrm{~dB}$ SPL and anyway in $97 \%$ of cases it was greater than $10 \mathrm{~dB}$ SPL. Such high amplitudes could be explained by the summation of spontaneous and evoked otoacoustic emissions $[21,22]$. On the other hand Bonfils [23], who recorded spontaneous emissions in $70 \%$ of normal new-borns, believes that low amplitudes of TEOAEs could indicate a cochlear damage. 
Table 2

A review of the literature with comparison of new-born age, stimulus level, reproducibility and pass rate

\begin{tabular}{|c|c|c|c|c|c|}
\hline Authors & No. ears & $\begin{array}{l}\text { New-born age (TEOAE } \\
\text { recording) }\end{array}$ & $\begin{array}{l}\text { Stimulus level (dB- } \\
\text { SPL) }\end{array}$ & $\begin{array}{l}\text { Reproducibility } \\
(\%)\end{array}$ & Pass rate $(\%)$ \\
\hline Kok et al. [27] & 20 & $36-108 \mathrm{~h}$ & $<96$ & $>100$ & 75 \\
\hline Lafreniere et al. [18] & 44 & 2-4 days & $82 \pm 4$ & $>70$ & 100 \\
\hline Thornton et al. [35] & 121 & 1-3 days & 70 & $>50$ & 70 \\
\hline White et al. [19] & 1850 & $24-48 \mathrm{~h}$ & $71-83$ & $>50$ & 73.1 \\
\hline Kok et al. [31] & 127 & $43-53-66$ weeks & $>72.5$ & $>40-50$ & 83 \\
\hline Aidan et al. [21] & 508 & 2-3 days & $78 \pm 4$ & $>60$ & $?$ \\
\hline Salamy et al. [33] & 267 & At nursery & 87 & $>50$ & 63.5 \\
\hline Doyle et al. [40] & 400 & $5-48 \mathrm{~h}$ & $85-95$ & $>50$ & 79 \\
\hline Present study & 640 & 4 days & $78-85$ & $>50$ & 77.2 \\
\hline
\end{tabular}

The pass-fail criteria described in the literature are quite variable and can be visual or numerical. The visual one is based upon the evaluation of the FFT of the response: the test is passed if the response is detectable in at least half of the extension of every frequential band of the whole spectrum. The most recent screening programs adopt as the most reliable criterion the reproducibility of the response within the frequency bands between 1000 and $4000 \mathrm{~Hz}$ [24]. The National Consortium on New-born Hearing Screening [25] suggested the option Quickscreen with reproducibility of $50 \%$ at $1600 \mathrm{~Hz}$ and of $70 \%$ or more at 2400,3200 and $4000 \mathrm{~Hz}$.

The correlation index of $50 \%$ was adopted by several authors [26,17,27,19], while others prefer correlations of $85 \%$ [28], $70 \%$ [18,29] and $60 \%$ [14].

We believe that the number of false alarms can be reduced both using higher correlation indexes or using a correlation index of $50 \%$ added to a spectral representation between 1000 and $5000 \mathrm{~Hz}$ and a response amplitude greater than $10 \mathrm{~dB}$ SPL. In the present paper we showed that the reproducibility of the response is high $(88 \pm 4 \%)$ if the test is correctly performed (stimulation, noise etc.).
A review of the literature shows that the pass rate is quite variable ranging from 52\% [17] to $98-99 \%$ [14,30] (Table 2). The pass rate of $77 \%$ at the first test obtained in the present study agrees with that obtained by most authors [31-33].

The single most important factor influencing the pass-rate of the test is the day of test performance as it's pass rate increases more than $50 \%$ between the first and the third day of life [34,35]. In fact during the first 4 days of life the external meatus cleans up spontaneously from the vernix caseosa. Maturation of cochlear mechanics [36,37], ending between the 29th and the 32nd gestational week $[23,38]$ may also be involved in the improvement of the response.

The technical factors able to significantly influence the results of the test are the coupling between the probe and the external meatus [9], the noise [17] and less frequently, a middle ear effusion $[15,39]$ that was present in $9 \%$ of cases without significant differences within the first days of life [40]. These authors observed that the prevalence of occlusion of the external meatus due to vernix caseosa was $14.3 \%$ within the first $24 \mathrm{~h}$, decreasing to $11.7 \%$ between the 25 th and the 48 th $\mathrm{h}$, while only $45 \%$ of new-borns showed a clean meatus during the first day of life. When the 
external meatus contained vernix caseosa the success rate of the test decreased to $38 \%$.

A universal hearing screening by means of TEOAEs poses several problems, concerning the standardization of the method and of the response evaluation. Moreover the activity of the Audiology Services is highly affected by screening and follow-up programs. In fact, if a universal screening is really performed, the rate of false alarms requiring an $\mathrm{ABR}$ is still too high with whatever screening test we choose. Moreover, the cost reductions cause an overall tendency to an earlier discharge of babies from the nursery (second-third day of life) thus reducing the possibilities of performing the test in the best conditions.

On the other hand a late diagnosis of congenital hearing loss is really not acceptable as hearing loss shows a higher incidence $(1-2 / 1000)$ than phenylketonuria $(1 / 12000)$ and hypothyroidism (1/3500) [41-43].

In conclusion, TEOAEs recording seems at now to be the test of choice for a universal hearing screening. A greater standardization of criteria both in performing the test and in evaluating the results is needed.

\section{References}

[1] Joint Committee on Infant Hearing 1994, Position statement, ASHA 6 (1994) 38-41.

[2] American Academy of Pediatrics. Joint Committee on Infant Hearing 1994, Position statement, Pediatrics 95 (1995) 152-156.

[3] D.J. Lyon, M.E. Yon, Early detection of hearing loss, Can. J. Public Health 73 (1982) 410-415.

[4] D.G. Pappas, A study of the high risk registry for sensorineural hearing impairment, Arch. Otolaryngol. Head Neck Surg. 91 (1983) 41-44.

[5] A. Parving, Epidemiology of hearing loss and audiological diagnosis of hearing impairment in childhood, Int. J. Pediatr. Otorhinolaryngol. 5 (1993) 159-165.

[6] D.T. Kemp, Stimulated acoustic emissions from within the human auditory system, J. Acoust. Soc. Am. 64 (1978) 1386-1391.

[7] N.J. Johnsen, P. Bagi, C. Elberling, Evoked acoustic emissions from the human ear III. Finding in neonates, Scand. Audiol. 12 (1982) 17-24.

[8] D.T. Kemp, S. Ryan, Otoacoustic emissions tests in neonatal screening programmes, Acta Otolaryngol. 482 (1991) 73-84.
[9] D.T. Kemp, S. Ryan, P. Bray, A guide to the effective use of otoacoustic emissions, Ear Hear 11 (1990) 93-105.

[10] R. Probst, B.L. Lonsbury-Martin, G.K. Martin, A review of otoacoustic emissions, J. Acoust. Soc. Am. 89 (1991) 2027-2067.

[11] F. Grandori, P. Ravazzani, Non linearities of clickevoked otoacoustic emissions and the derived non linear response, Br. J. Audiol. 27 (1993) 97-102.

[12] P. Ravazzani, F. Grandori, Evoked otoacoustic emissions: non linearities and response interpretation, IEEE Trans. Biomed. Eng. 40 (1993) 5.

[13] P. Bonfils, A. Dumont, P. Marie, M. Francois, P. Narcy, Evoked otoacoustic emissions in new-born hearing screening, Laryngoscope 100 (1990) 28-33.

[14] D. Aidan, P. Lestang, P. Avan, P. Bonfils, Characteristics of transient-evoked otoacoustic emissions (TEOAEs) in neonates, Acta Otolaryngol. (Stockh) 117 (1997) 25-30.

[15] K.W. Chang, B. Vohr, S.J. Norton, M.D. Lekas, External and middle ear status related to evoked otoacoustic emission in neonates, Arch. Otolaryngol. Head Neck Surg. 119 (1993) 276-282.

[16] M. Fabiani, G.P. Bertoli, Le otoemissioni acustiche evocate in audiologia infantile. Metodica di registrazione, strumentazione ed interpretazione delle TEOAE, Relazione Ufficiale del XXIII Congresso Nazionale S.I.A, 1994, pp. $142-156$.

[17] J.T. Jacobson, C.A. Jacobson, The effects of noise in transient EOAE new-born hearing screening, Int. J. Pediatr. Otorhinolaryngol. 29 (1994) 235-248.

[18] D. Lafreniere, M.D. Jung, J. Smurzynski, G. Leonard, D.O. Kim, J. Sasek, Distortion product and click-evoked otoacoustic emissions in healthy new-borns, Arch Otolaryngol. Head Neck Surg. 117 (1991) 1382-1389.

[19] K.R. White, B.R. Vohr, A.B. Maxon, T.R. Behrens, M.G. McPherson, G.W. Mauk, Screening all new-borns for hearing loss using transient evoked otoacoustic emissions, Int. J. Pediatr. Otorhinolaryngol. 9 (1994) 203-217.

[20] J.C. Stevens, H.D. Webb, J. Hutchinson, J. Connell, M.F. Smith, J.T. Buffin, Click evoked otoacoustic emissions in neonatal screening, Ear Hear 11 (1990) 128-133.

[21] D. Aidan, A. Lucek, M. El-Bez, P. Lestang, S. Parrat, A. Pascu, P. Avan, P. Bonfils, Définition des critères de normalité d'une oto-émission acoustique provoquée chez le nouveau-né, Ann. Otolaryngol. Chir. Cervicofac. 112 (1995) 305-308.

[22] T. Morlet, L. Collet, R. Duclaux, A. Lapillonne, B. Salle, G. Petet, A. Morgon, Spontaneous and evoked otoacoustic emissions in pre-term and full-term neonates: is there a clinical application?, Int. J. Ped. Otorhinolaryngol. 33 (1995) 207-212.

[23] P. Bonfils, M. Francois, P. Avan, A. Londero, J. Trotoux, P. Narcy, Spontaneous and evoked otoacoustic emissions in pre-term neonates, Laryngoscope 102 (1992) 182-186.

[24] B. Culpepper, Neonatal screening via evoked otoacoustic emissions, in: M.S. Robinette, T.J. Glattke (Eds.), Otoacoustic emissions: clinical applications, Thieme, New York, 1997, pp. 233-270. 
[25] B. Culpepper, Neonatal screening via evoked otoacoustic emissions. (National Consortium for New-born Hearing Screening (1995, November 16-18). TEOAE-based universal new-born hearing screening. Georgetown University School of Medicine. Washington, DC. 1995), in: M.S. Robinette, T.J. Glattke (Eds.), Otoacoustic Emissions: Clinical Applications, Thieme, New York, 1997, p. 271.

[26] T.J. Glattke, I.A. Pafitis, C. Cummiskey, G.R. Herer, Identification of hearing loss in children using measures of transient otoacoustic emission reproducibility, Am. J. Audiol. 4 (1995) 71-86.

[27] M.R. Kok, G.A. van Zanten, M.P. Brocaar, H.C.S. Wallemburg, Click-evoked otoacoustic emissions in 1036 ears of healthy new-borns, Audiology 32 (1993) 213-224.

[28] S.J.R.C. Decreton, K. Hanssens, M. De Sloovere, Evoked otoacoustic emissions in infant hearing screening, Audiology 33 (1994) 152-164.

[29] E. Molini, G. Ricci, N. Alunni, C. Simoncelli, B. Brunelli, Risultati e considerazioni a proposito dello screening neonatale basato sull'impiego delle otoemissioni acustiche evocate da transienti, Acta Otorhinolaryngol. Ital. 17 (1997) 1-8.

[30] A.B. Maxon, K.R. White, L.B. Montensen, T.R. Behrens, Feasibility of identifying risk for conductive hearing loss in a new-born universal screening program, Semin. Hear 14 (1993) 73-87.

[31] M.R. Kok, G.A. van Zanten, M.P. Brocaar, H.T.M. Jogejan, Click evoked otoacoustic emissions in very low birthweight infants: a cross sectional data analysis, Ear Hear 17 (1994) 42-48.

[32] E.L. McNellis, A.J. Klein, Pass/fail rates for repeated click-evoked otoacoustic emission and auditory brainstem response screenings in new-borns, Otolaryngol. Head Neck Surg. 116 (1997) 431-437.

[33] A. Salamy, L. Eldredge, A. Sweetow, Transient evoked otoacoutic emissions, feasibility in the nursery, Int. J. Pediatr. Otorhinolaryngol. 21 (1996) 235-247.

[34] C. Simoncelli, E. Molini, G. Ricci, B. Capolunghi, N. Alunni, N. Trabalza, Les otoemissions acoustiques évoquées pendant les 60 premières heures de vie, Acta OtoRhino-Laringol. Bel. 46 (1992) 63-66.
[35] A.R.D. Thornton, L. Kimm, C.R. Kennedy, D. CafarelliDess, External and middle-ear factors affecting evoked otoacoustic emissions in neonates, Br. J. Audiol. 27 (1993) 319-327.

[36] S.W. Chuang, S.E. Gerber, A.R.D. Thornton, Evoked otoacoustic emissions in pre-term infants, Int. J. Pediatr. Otorhinolaryngol. 26 (1993) 39-45.

[37] G. Salomon, B. Anthonisen, J. Groth, P.P. Thomsen, Otoacoustic hearing screening in new-borns optimization, in: F.H. Bess, J.K. Hall (Eds.), Otoacoustic emissions, Wilkerson Center Press, 1992, pp. 191-206.

[38] M.C. Whitehead, Development of the cochlea, in: R.A. Altshuler, D.W. Hoffman, R.P. Bobbin (Eds.), Neurobiology of Hearing, Raven Press, New York, 1986, pp. $191-211$.

[39] A. El Refaie, D.J. Parker, J.M. Bamford, Otoacoustic emission versus ABR screening: the effects of external and middle ear abnormalities in a group of SCBU neonates, Br. J. Audiol. 30 (1996) 3-8.

[40] K.J. Doyle, B. Burggraaff, S. Fujikawa, J. Kim, C.J. Macarthur, Neonatal hearing screening with otoscopy, auditory brain stem response, and otoacoustic emissions, Otolaryngol. Head Neck Surg. 116 (1997) 597-603.

[41] E. Cacciari, A. Cao, G.B. Cavazzuti, P. Nicola, F. Panizon, G. Segni, F. Zacchello, Screening neonatali, in: E. Cacciari, A. Cao, G.B. Cavazzuti, P. Nicola, F. Panizon, G. Segni, F. Zacchello (Eds.), Principi e Pratica di Pediatria, Monduzzi, Bologna, 1990, pp. 301-302.

[42] P. Davidson, M. Hyde, P. Alberti, Epidemiologic patterns in childhood hearing loss: a review, Int. J. Pediatr. Otorhinolaryngol. 17 (1989) 239-266.

[43] A. Davis, S. Wood, R. Healy, H. Webb, S. Rowe, Risk factors for hearing disorders: epidemiological evidence for a change over time in the UK, J. Am. Acad. Audiol. 6 (1995) 365-370.

[44] M.E. Lutman, A.C. Davis, M. Fortnum, S. Wood, Field sensitivity of targeted neonatal hearing screening by transient-evoked otoacoustic emissions, Ear Hear 18 (1997) $265-276$. 